\title{
NOTES ON BOOKS.
}

$W_{\mathrm{E}}$

(Macmillane the first volume of the Archives of the Middlesex Hospital a small edit \&o., London, 1903), which appears under the direction of This issuedorial committee, with Dr. J. Kingston Fowler as chairman. interest. contains eleven short articles of much practical and scientific $W_{\mathrm{e}}$ are It is intended to issue not less than four volumes annually. former sure that if the standard set by the first volume is maintained, all They are students of Middlesex will desire to possess these Archives. illustrated.

In a

points in thall brochure Oppenheimer draws attention to some practical (Rebman the diagnosis and treatment of Gonorrhoea in the Male fast to the old London, 1903). The author apparently inclines to hold appears to older methods of treatment, which, in the course of what The so-called been a fairly wide experience, he has found satisfactory. anterior ulled abortive methods of treatment, the use of irrigation in ${ }^{s} c_{0}$ pe, he holds is as advocated by Janet, and the merits of the urethro-

Mindall, Anne Ellison's Manual for Students of Massage (Baillière, Gullielma Max, London, 1904) appears in a second edition, revised by tion of the Manley. The first half of the book is devoted to the descripto meet the anamy and physiology of the body, given in sufficient detail simly described, and the masseuse. The various manipulations are youle diagrams is in the indications for each pointed out. A series of Don'ts masseuse in introduced, and will materially aid the student. The mass," to be found on p. 95. We are not familiar with the verb "to the author repeatedly employs.

Ltd., Useful little work on First Aid in Accidents (George Gill \& Sons adapted for thas been written by Collie and Wightman. It is specially aseful feature is the who use the London School Board Syllabus. A Pended to each the series of questions, with appropriate answers, Hospital, ${ }^{\text {Pactical Nursing, by Isla Stewart, Matron of St. Bartholomew's }}$ H. E. Cuff, M.D., F.R.C.S. (William Blackwood \& Sons, 
Edinburgh and London, 1903), is a useful guide to nurses entering on their studies. It is clearly written, accurate, and well up to date.

Dr. Jex Blake has done well to reissue her small book on The Care of Infants (George A. Morton, Edinburgh). This manual for mothers and nurses is full of wise advice, the result of the author's long experience, and should be in the hands of all to whom the care of infants is entrusted.

The Home Nurse, by S. F. A. Caulfield (Elliot Stock, London, 1903), is the work of an amateur, and is doubtless written with the best intentions. The chapters reprinted from the Girls' Own Paper, and the poem entitled "The Star of India," can do no harm to any one, but we cannot say the same of the rest of the book. It contains too many gratuitous advertisements of quack medicines to be placed with safety in the hands of lay readers.

The new (eighth) edition of Mr. Ince's Latin Grammar of Pharmacy (Baillière, Tindall, \& Cox, London, 1903) has been rearranged and considerably enlarged. Its value to students of pharmacy is still further enhanced by the addition of an English-Latin vocabulary.

The fact that Dorland's Pocket Medical Dictionary (W. B. Saunder's $\&$ Co., London and New York, 1903) has gone through four editions in as many years sufficiently attests its value. We have subjected it to several crucial tests, and have rarely found it wanting. Among other useful features may be mentioned a series of tables of doses, weights and measures, temperature scales, arteries, nerves, and muscles, which are extremely convenient for hurried reference.

Students, house-surgeons, and others will find Dr. Melland's Pocketbook of Clinical Methods (John Wright \& Co., Bristol, 1903) a handy and reliable guide to the examination of sputum, urine, pus, blood, etc., for clinical purposes.

The Examination of the Urine, by Dr. J. K. Watson (The Scientific Press Ltd., London), is addressed to nurses, and contains a very useful description of the naked-eye appearances of the urine in health and disease, which every nurse will do well to study. If it is considered advisable that the chemical analysis of the urine should be entrusted to the nurse, she will find in this little work a helpful and reliable guide. 